\title{
ER $\alpha$ activity depends on interaction and target site corecruitment with phosphorylated CREB1
}

\author{
Melissa Berto ${ }^{1}$, Valerie Jean ${ }^{1}$, Wilbert Zwart ${ }^{2}$, Didier Picard ${ }^{1}$ (B)
}

\begin{abstract}
The two transcription factors estrogen receptor $\alpha(E R \alpha)$ and cyclic adenosine monophosphate (CAMP)-responsive element binding protein 1 (CREB1) mediate different signals, bind different response elements, and control different transcriptional programs. And yet, results obtained with transfected reporter genes suggested that their activities may intersect. We demonstrate here that CREB1 stimulates and is necessary for ER $\alpha$ activity on a transfected reporter gene and several endogenous targets both in response to its cognate ligand estrogen and to ligand-independent activation by CAMP. The stimulatory activity of CREB1 requires its DNA binding and activation by phosphorylation, and affects the chromatin recruitment of ER $\alpha$. CREB1 and ER $\alpha$ are biochemically associated and share hundreds to thousands of chromatin binding sites upon stimulation by estrogen and CAMP, respectively. These shared regulatory activities may underlie the anti-apoptotic effects of estrogen and CAMP signaling in ER $\alpha$-positive breast cancer cells. Moreover, high levels of CREB1 are associated with good prognosis in ER $\alpha$-positive breast cancer patients, which may be because of its ability to promote ER $\alpha$ functions, thereby maintaining it as a successful therapeutic target.
\end{abstract}

DOI 10.26508/lsa.201800055 | Received 8 March 2018 | Revised 18 May 2018 | Accepted 22 May 2018 | Published online 7 June 2018

\section{Introduction}

Estrogen receptor $\alpha(E R \alpha)$ and CAMP-responsive element binding protein 1 (CREB1) are two unrelated transcription factors that, at first sight, have nothing to do with each other. ERa is a member of the nuclear receptor superfamily; in response to binding its cognate ligand estrogen, it is activated as a transcription factor and binds as a homodimer to specific DNA sequences across the genome to regulate target genes (Heldring et al, 2007; Flach \& Zwart, 2016). CREB1 and other family members such as ATF1 contain a basic region for binding DNA followed by a leucine zipper for homo- or heterodimerization; as its name indicates, it is a paradigmatic target of the CAMP-activated PKA. Upon phosphorylation of serine 133 by PKA, pCREB1 can specifically recruit the coactivator CREB binding protein (CBP) and its paralog p300 (Mayr \& Montminy, 2001). Thus, whereas $E R \alpha$ is typically a ligand-activated transcription factor, CREB1 is signal responsive through phosphorylation. Intriguingly, unliganded ER $\alpha$ can also be activated by CAMP signaling in the absence of estrogens (Power et al, 1991; Aronica \& Katzenellenbogen, 1993; Smith et al, 1993; Lazennec et al, 2001; Dudek \& Picard, 2008; Carascossa et al, 2010; de Leeuw et al, 2013). We had found this extreme form of signaling crosstalk to be dependent on the PKAmediated phosphorylation of the coregulators CARM1 (Carascossa et al, 2010) and LSD1 (Bennesch et al, 2016), but could not exclude that yet other factors might be involved (Bennesch \& Picard, 2015).

CREB1 not only controls the expression of its own direct target genes (Mayr \& Montminy, 2001; Zhang et al, 2005), but is also involved in signaling crosstalk with nuclear receptors such as the glucocorticoid receptor (GR) (Akerblom et al, 1988) and ERa (Lazennec et al, 2001). Whether CREB1 stimulates or represses nuclear receptor activity seems to be cell-context dependent (Lazennec et al, 2001; Diaz-Gallardo et al, 2010; Ratman et al, 2013). Similarly, ERo interacts with a variety of transcription factors (Heldring et al, 2007, 2011), be it by tethering to them on their target sites, such as in the case of the Jun/Fos heterodimer AP-1 (Kushner et al, 2000) and SP1 (Saville et al, 2000), or through a variety of other, not always well-characterized mechanisms. ER $\alpha$ and the NF-KB display both positive and negative interactions (Kalaitzidis \& Gilmore, 2005; Franco et al, 2015), as do ERa and the retinoic acid receptors at the level of chromatin binding (Hua et al, 2009; Ross-Innes et al, 2010). The crosstalk between GR and ER $\alpha$ may be highly context dependent because GR has been demonstrated to repress some of the ER $\alpha$ program by disrupting its transactivation complexes (Yang et al, 2017) and to stimulate some ERa responses by promoting chromatin remodeling such that ER $\alpha$ loading is facilitated (Voss et al, 2011; Swinstead et al, 2016a).

In view of the fact that both ER $\alpha$ and CREB1 mediate PKAmediated CAMP signaling and considering previous reports on their crosstalk (Lazennec et al, 2001; Heldring et al, 2011), we decided to explore the mechanism and the physiological or pathological significance of signaling crosstalk in more detail. Because ER $\alpha$ is a key proliferative factor in breast cancer, we chose ER $\alpha$-positive breast cancer cells as cellular model system.

'Département de Biologie Cellulaire and Institute of Genetics and Genomics of Geneva, Université de Genève, Genève, Switzerland ${ }^{2}$ Division of Oncogenomics, Oncode Institute, Netherlands Cancer Institute, Amsterdam, The Netherlands

Correspondence: didier.picard@unige.ch 


\section{Results}

\section{CREB1 stimulates the transcriptional activity of the liganded and unliganded ER $\alpha$}

To confirm and characterize further the positive contribution of CREB1 to ER $\alpha$ activity (Lazennec et al, 2001), we performed luciferase reporter assays with the human ER $\alpha$-positive breast cancer cell line MDA-MB-134 (Reiner \& Katzenellenbogen, 1986). Cells were transfected with luciferase reporters without an estrogen responsive element (LUC), with an estrogen responsive element (ERE-LUC), or with a CREB responsive element (CRE-LuC) (Fig 1). Cells were treated either with the physiological estrogen 17ß-estradiol (E2) or with a cocktail of the adenylate cyclase activator forskolin and the phosphodiesterase inhibitor 3-isobutyl-1-methylxanthine (FI) to boost intracellular levels of cAMP. As expected (Dudek \& Picard, 2008; Carascossa et al, 2010; Bennesch et al, 2016), ER $\alpha$ is transcriptionally activated by both treatments (Fig 1A); CREB1 is only activated by CAMP and E2-activated ER cannot activate transcription through a CRE (Fig 1B). Without a response element, only basal activity could be observed (Fig 1C). Overexpression of wildtype CREB1 increases the activity of both ER $\alpha$ and CREB1 luciferase reporters, whereas overexpression of a dominant-negative form of CREB1 (A-CREB1), which is deficient in DNA binding because it lacks the basic region $\mathrm{N}$-terminal to the leucine zipper dimerization domain (Ahn et al, 1998), reduces reporter activities (Fig 1A-C). Note that ER $\alpha$ levels are not affected by the overexpression of CREB1 (see below). Because CREB1 transcriptional activity is stimulated by phosphorylation of a conserved serine (Ser133) by cAMP-activated PKA, we tested whether this residue is important for the contribution of CREB1 to ER $\alpha$ activity. Therefore, we overexpressed either a phosphoserine-deficient mutant CREB1 (CREB1-S133A) or a phosphoserine-mimetic mutant
CREB1 (CREB1-S133D) (Fig S1A). The luciferase reporter assays of Fig 1 show that the non-phosphorylatable CREB1 mutant, acting as a dominant-negative mutant, reduces both ER $\alpha$ and CREB1 activities and that the phosphoserine-mimetic CREB1 mutant stimulates ER $\alpha$ similarly to wild-type CREB1. Conversely, when CREB1 was knocked down by RNA interference (Fig S1B-C), the luciferase activities of both reporters were decreased (Fig 1D). E2 does not seem to be able to promote the association of ER $\alpha$ with the DNA-bound CREB1 or to activate the CRE-Luc reporter; unlike what has been reported by others (Heldring et al, 2011), ERa is apparently unable to work by tethering under our experimental conditions. Note that based on experiments with two of the CREB1 mutants and exogenous expression of ER $\alpha$, we conclude that CREB1 is also required for ER $\alpha$ function in ER $\alpha$-negative HEK293T cells (Fig S2). Overall, these results indicate that CREB1 is both sufficient to boost ER $\alpha$ activity and necessary for its activity in response to either E2 or CAMP and that it is CREB1 itself, rather than other members of its family, that is involved.

Having demonstrated the importance of CREB1 for a transfected ERa reporter gene, we next evaluated this for endogenous ER $\alpha$ target genes (Fig 2). Overall, the overexpression of wild-type CREB1 or the CREB1 mutants A-CREB1 and S133A had the same effects on three representative ERa target genes (Fig 2A-C). The impact of the CREB1 mutant S133D on endogenous target genes induced by CAMP again recapitulated its effects on the transfected reporter gene, but S133D reduced the response to E2 for the three genes examined here. The latter finding may be a result of substantial differences in experimental conditions such as timing and context between the two types of experiments. Again, as for the transfected reporter, the knockdown of CREB1 dramatically reduced the activation of the ER $\alpha$ target genes NFKB2, TFF1, and GREB1 (Fig 2D). Remarkably, the expression of the two ER $\alpha$ target genes $A B C A 3$ and NRIP1, which are only activated in response to $E 2$, are only minimally affected by the CREB1 knockdown.
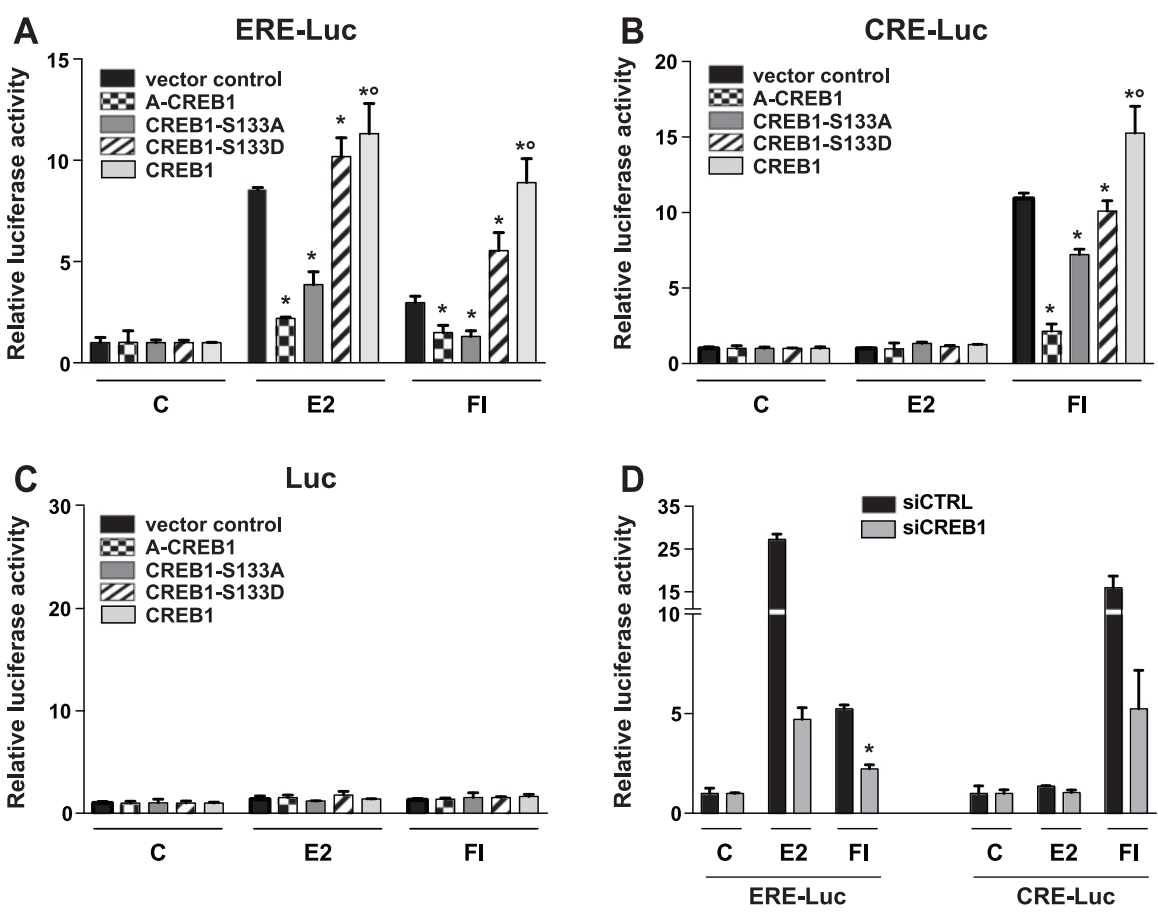

Figure 1. CREB1 promotes ER $\alpha$ transcriptional activity.

(A-C) The overexpression of exogenous CREB1 increases both ERa and CREB1 activities. Luciferase reporter assays in MDA-MB-134 breast cancer cells with endogenous $E R \alpha$. Cells were cotransfected with a luciferase reporter fused to either an $\operatorname{ERE}(\mathrm{A})$ or a CRE (B), or with a luciferase reporter lacking a specific response element (C), and with CREB1 expression vectors as indicated. Cells were stimulated with vehicle alone (DMSO, indicated with a C), $\mathrm{E} 2$, or $\mathrm{Fl}$ as indicated in the Materials and Methods section. (D) Effect of transient siRNA-mediated knockdown of CREB1 on ER $\alpha$ and CREB1 activities. Luciferase reporter assays with transfected MDA-MB-134 cells, treated as indicated. All values marked with an asterisk are statistically significantly different from their respective vector or siRNA controls with $P$-values $<0.05$; those marked with a small circle are significantly different from the S133D sample. 

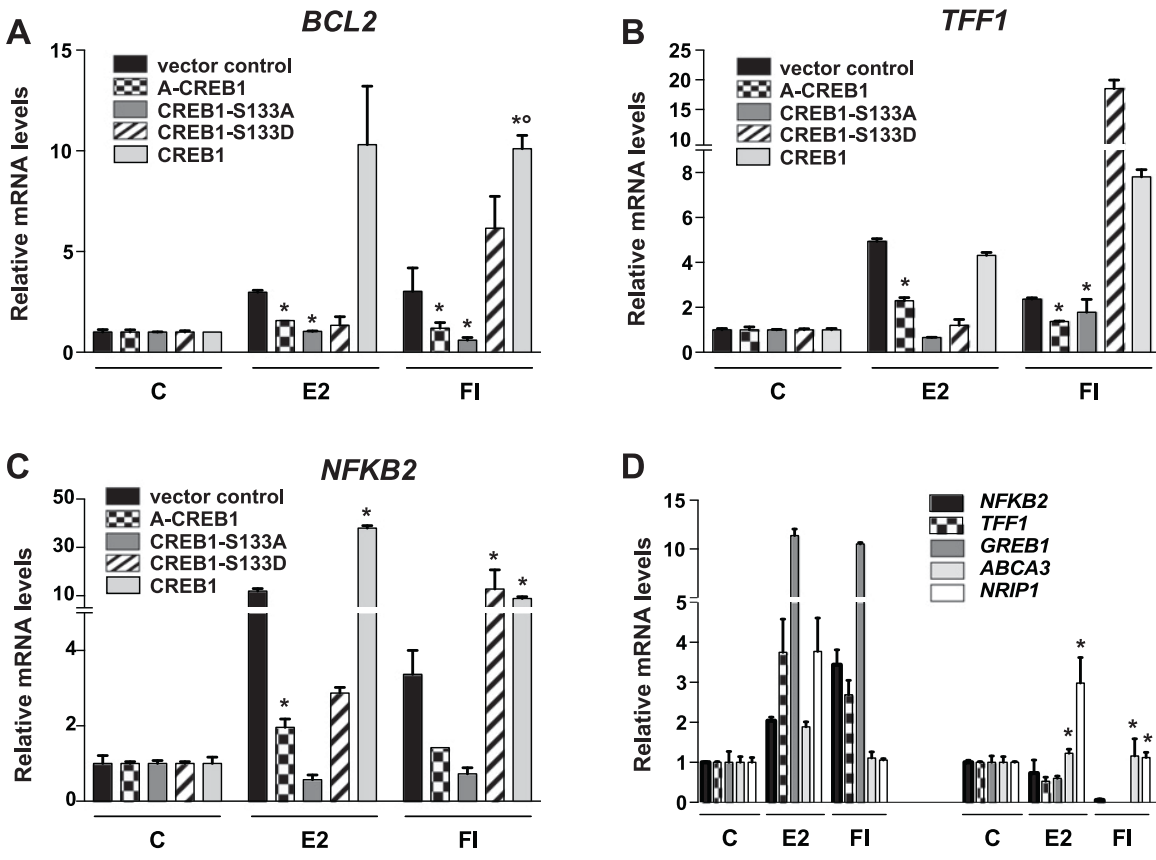

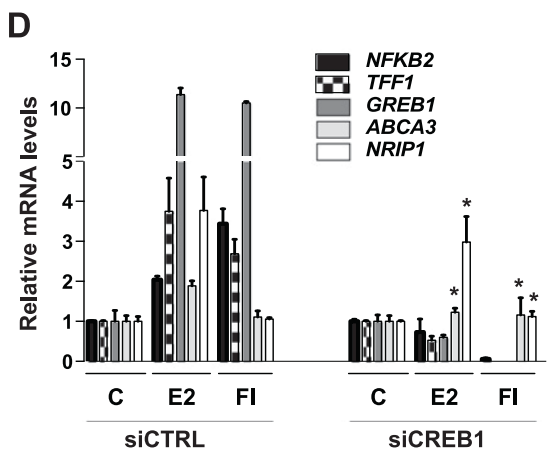

Figure 2. CREB1 promotes the induction of endogenous $E R \alpha$ target genes.

(A-C) CREB1 overexpression promotes the expression of the indicated ER $\alpha$ target genes. MDA-MB-134 cells were transfected with the indicated expression vectors and stimulated with vehicle, E2, or FI for $6 \mathrm{~h}$ before extraction of RNA for quantitative RT-PCR analysis of the indicated $E R \alpha$ target genes. See the Materials and Methods section for more experimental details. All values marked with an asterisk are statistically significantly different from their respective vector or siRNA controls with $P$-values $\leq 0.05$; those marked with a small circle are significantly different from the S133D sample. (D) Effect of transient siRNA-mediated knockdown of CREB1 on the expression of a panel of ERa target genes, as determined by quantitative RT-PCR analysis; cells and treatments as in panels A-C. All values marked with an asterisk are statistically significantly different from their respective siRNA controls with $P$-values $<0.05$
We then aimed to determine which ER domains functionally collaborate with CREB1. For this purpose, we used a series of vectors expressing different ER $\alpha$ domains fused to the heterologous Gal4 DNA-binding domain (Fig S3). To avoid interferences with endogenous ERa, we switched to ERa-negative HEK293T cells. We found that only the fusion protein containing the ER hormone-binding domain (HBD) (Fig S3E) responds to the overexpression of wild-type and mutant CREB1 similarly to wild-type ER $\alpha$ in our previous experiments. Full-length CREB1, as a fusion protein with the Gal4 DNA-binding domain, served as a control and responded like the endogenous CREB1 (Fig S3F).

Taken together, these results are consistent with an earlier report that had primarily focused on the synergy between E2 and CAMP (Lazennec et al, 2001); they extend it to the hypothesis that CREB1 plays a crucial role in promoting ERa activity in response to both E2 and CAMP. This appears to depend on CREB1 DNA binding and its phosphorylation on S133 by PKA and on the ER $\alpha$ HBD.

\section{CREB1 influences ER $\alpha$ recruitment to chromatin}

The next experiments were designed to explore the underlying molecular mechanisms. We performed chromatin immunoprecipitation (ChIP) experiments with MDA-MB-134 cells to see whether CREB1 influences the recruitment of ER $\alpha$ to endogenous ER $\alpha$ target genes (Fig 3). The results are consistent with the effects on ER $\alpha$-mediated target gene expression. Overexpression of wildtype CREB1 leads to a massive increase in ER $\alpha$ recruitment to ER $\alpha$ binding sites associated with the genes TFF1, GREB1, and NFKB2. In contrast, the overexpression of the mutants A-CREB1 or S133A essentially annihilates ERa recruitment to these same sites; this is very clear, despite some variability in ERa recruitment with the distinct empty vector controls of these separate experiments (Fig $3 A-C)$. The siRNA-mediated knockdown of CREB1 reduced the recruitment of ERa to those test genes (Fig 3D) whose expression is reduced by CREB1 knockdown (Fig 2D). Interestingly, the recruitment of ER $\alpha$ to the subset of ER $\alpha$ target genes, $A B C A 3$ and NRIP1, whose expression is not regulated by CAMP (Fig 2D) was not perturbed by the knockdown of CREB1. This indicates that recruitment to chromatin targets and transcriptional activation can be distinct steps, notably for the expression of some ER $\alpha$ target genes in response to CAMP. Similar results could be obtained with MCF7 cells; the effects of overexpression of CREB1 or CREB1 mutants and of the shRNA-mediated knockdown of CREB1 on ER $\alpha$ recruitment to three target genes point out a comparable requirement for ER $\alpha$ in this unrelated ER $\alpha$-positive breast cancer cell line (Fig S4).

\section{ER $\alpha$ and CREB1 interact}

Our results suggested that ER $\alpha$ might interact with CREB1. We could demonstrate with co-immunoprecipation experiments that pCREB1 is associated with endogenous ERa in MDA-MB-134 cells and that this interaction is stimulated by both E2 and CAMP (Fig $4 A$ ). This interaction may also involve CARM1, an ERa coactivator whose interaction with ER $\alpha$ is known to be stimulated by E2 and cAMP (Chen et al, 2000; Lee et al, 2005; Carascossa et al, 2010; Bennesch et al, 2016). We not only see a stimulation of the coimmunoprecipitation of ER $\alpha$ with CARM1 by activation of ER $\alpha$, we also see a specific co-immunoprecipitation with CARM1 of PCREB1, whose total amounts are increased by treatment of the cells with FI (Fig 4B and C). Essentially the same stimulated interaction of ER $\alpha$ with CREB1 is observed with exogenously expressed HA-tagged CREB1 (Fig 4D), but intriguingly, the interaction with 

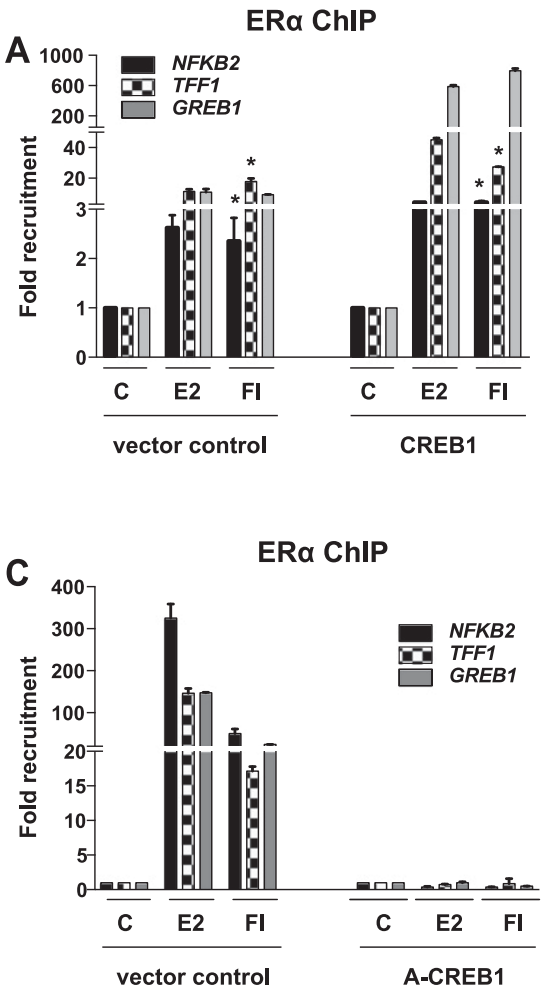

ERa ChIP
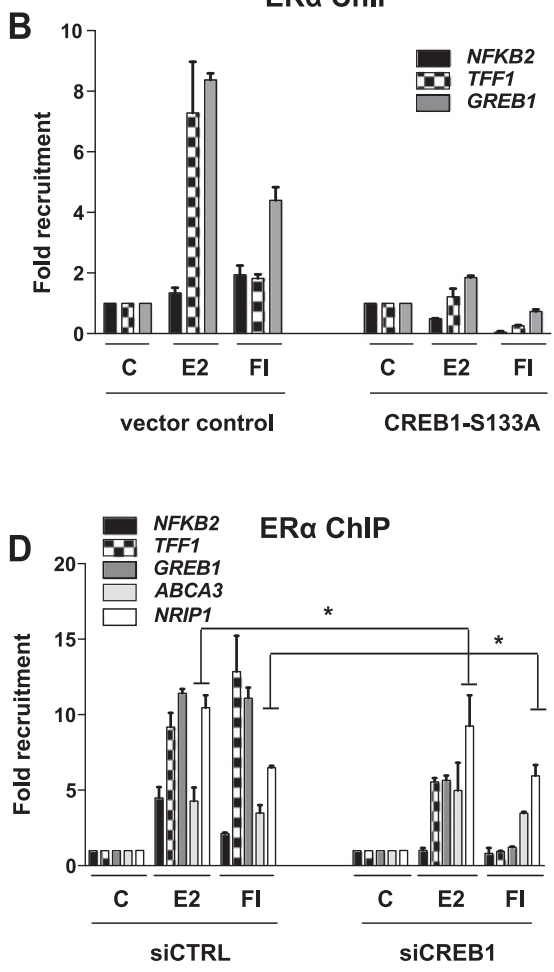

Figure 3. CREB1 promotes the recruitment of ER $\alpha$ to some target genes.

(A-C) ChIP-qPCR assays to determine the importance of CREB1 and its phosphorylation on S133 for the recruitment of ERa to target genes. MDA-MB-134 cells were transfected and treated as indicated in the figure and in the Materials and Methods section. Note that the fold recruitment values for ER $\alpha$ are experimentally variable between different experiments; these values should only be compared between different treatments and conditions within the same experiment/panel. (D) ChIP-qPCR assays to determine the impact of a siRNAmediated knockdown of CREB1 on the recruitment of ERa to a wider panel of target genes. CREB1 was knocked down in MDA-MB-134 cells before stimulation as indicated. All values marked with an asterisk are statistically significantly different from their respective vector or siRNA controls with $P$-values $<0.05$.
CREB1 S133A can only be revealed upon treatment with E2 (Fig 4E). In contrast, the S133D mutant displays a weak constitutive interaction, which can be further boosted with E2 (Fig 4F). We conclude from these experiments that ER $\alpha$ and CREB1 are part of a complex, which is likely to include yet other factors such as CARM1 (see also below) and whose assembly is stimulated by the activation of ER $\alpha$ and promoted by phosphorylation of CREB1 in signal-specific ways.
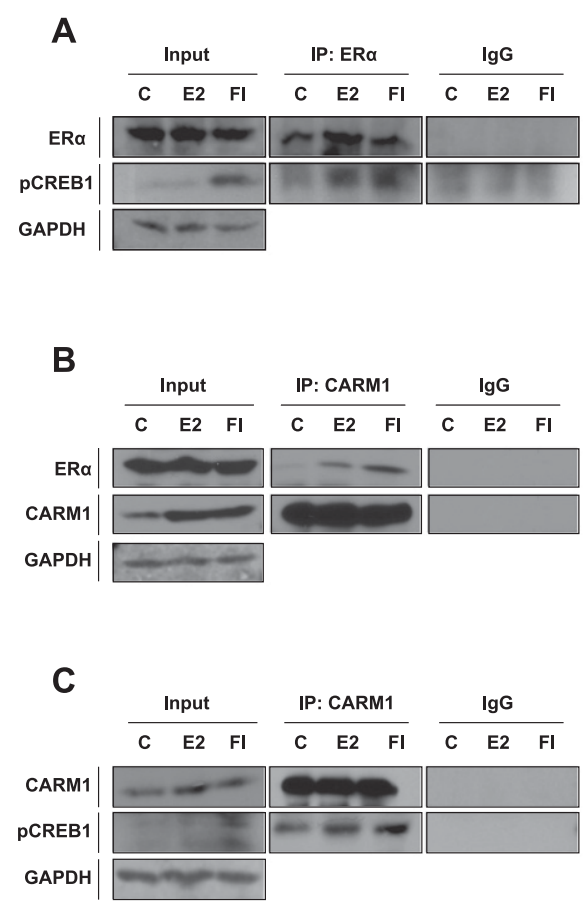
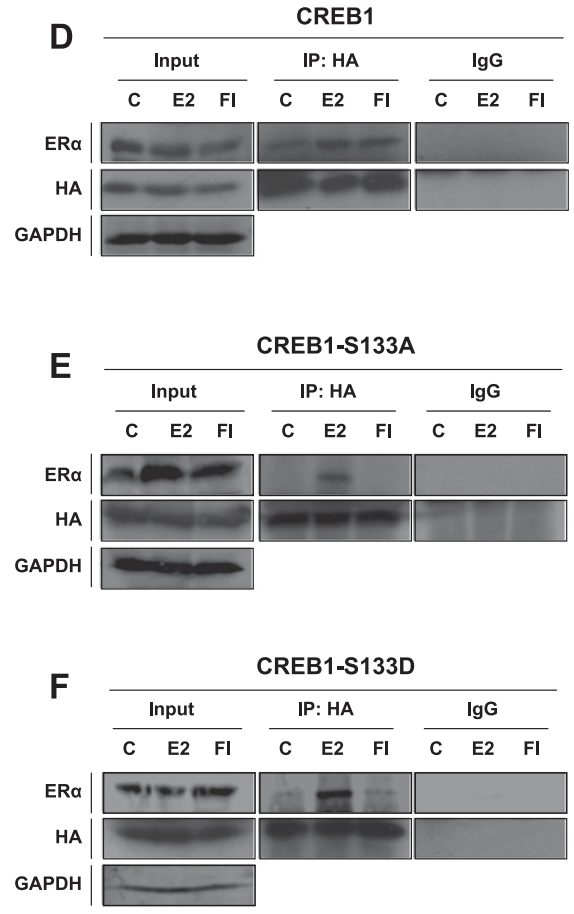

Figure 4. ER $\alpha$, CREB1, and CARM1 interact in a stimulus-dependent manner.

(A-C) Co-immunoprecipitation of endogenous ERa, CARM1, and PCREB1 as a function of stimulus. MDAMB134 cells were stimulated with DMSO (indicated by a C), E2, or Fl before cell lysis and immunoprecipitation as indicated in the figure and in the Materials and Methods section. Immunoprecipitations were performed with the antibodies indicated above the immunoblots, that is, either antibodies against ERa or CARM1 or a corresponding control antibody (IgG). Proteins revealed by immunoblotting are indicated on the left. (D-F) ERa as a function of stimulus. Exogenous HA-tagged wild-type and mutant CREB1 were immunoprecipitated from extracts of transfected MDAMB-134 cells to assess the association with endogenous ERa by immunoblotting with an antibody against the HA tag or ERa. 


\section{ERa/pCREB1 crosstalk at the genome-wide level}

To explore the synergy between ER $\alpha$ and PCREB1 at the genomewide level, we performed ChIP-seq experiments with MDA-MB-134 cells (Fig 5). As expected, the binding of both transcription factors significantly changed upon either E2 or CAMP stimulation (Fig 5). This is most striking for PCREB1, which exhibits a major increase once cells are stimulated with CAMP (>3,500 events), compared with E2 (<500) (Fig 5B, D, and F). Opposite effects were found for ER $\alpha$, where the $E 2$ response leads the receptor to occupy more than 20,000 binding sites (Fig 5A, C, and E). pCREB1 is recruited to more than 2,000 ER $\alpha$-binding sites of which the majority is induced by $\mathrm{FI}$ treatment (Fig 6A). Indeed, more than half (55\%) of the pCREB1 target sites stimulated by only CAMP are shared with ER $\alpha$ binding events (Fig 6B). Unlike FI, E2 treatment prompted pCREB1 to occupy only a small part (0.6\%) of the huge number of stimulated $E R \alpha$ target sites, even though $50 \%$ of those events are shared between the two transcription factors (Fig 6C). An indication of the functional context of the ER $\alpha$ or PCREB1 binding sites could be obtained by determining the genomic distribution of their binding sites (Figs S5 and $6 \mathrm{D}$ ). In the absence of stimulation, the binding sites for PCREB1 were significantly enriched at promoters and distant intergenic regions, of which many could correspond to enhancers, and in 5' UTR regions. The E2- or CAMP-induced sites did not show the apparent promoter and/or 5' UTR enrichment and retained a genomic distribution that was similar to that of ERa. The genomic distribution of the shared binding sites also showed a strong enrichment at promoters and at distant intergenic regions upon E2 stimulation whereas that of the ligand-independent binding sites was similar to the non-induced ones (Fig 6D).

In view of validating the ChIP-seq data for some selected genes, which are associated with coinciding ER $\alpha$ and pCREB1 peaks, we extracted the data for the three ER $\alpha$ target genes NFKB2, TFF1, and GREB1 (Fig 6E). These data could be confirmed by targeted ChIP-
A

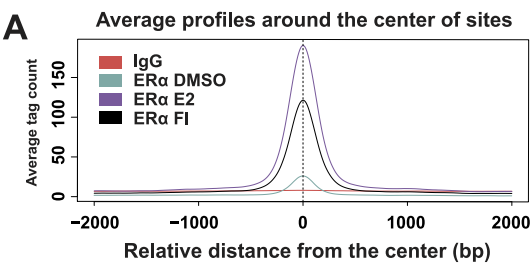

C

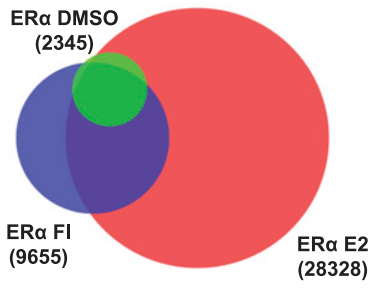

ER $\alpha$ DMSO only (61 locations)

ERa FI only (3172 locations)

ER $\alpha 2$ only (21603 locations)

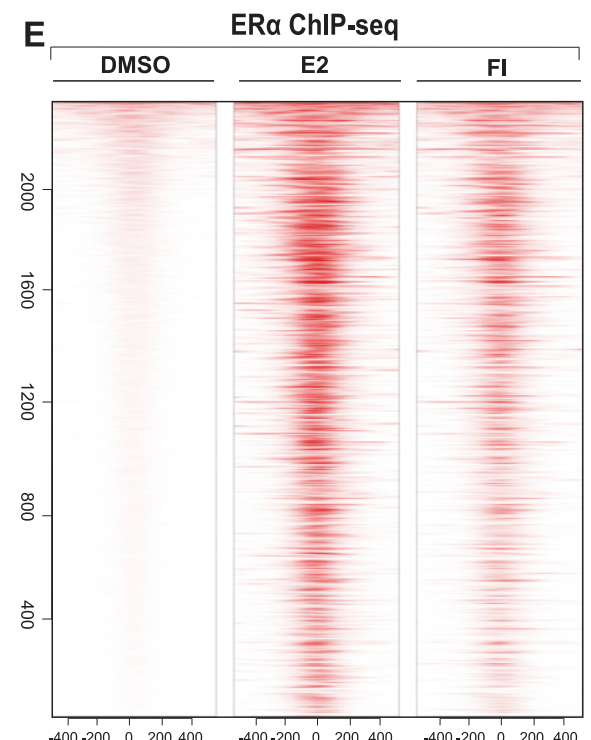

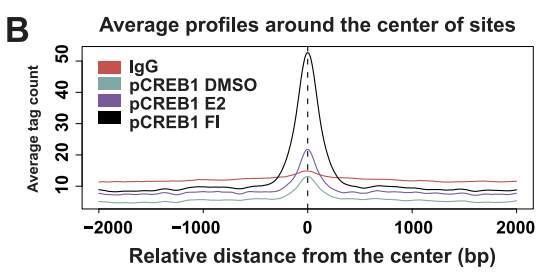

D

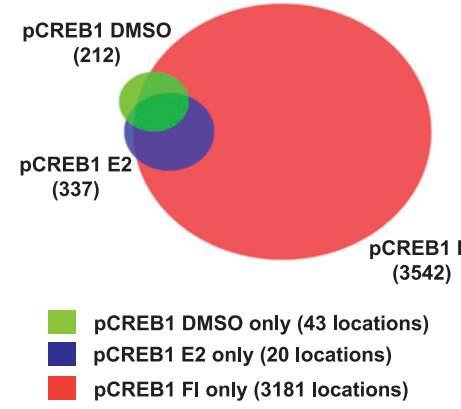

$\mathbf{F}$

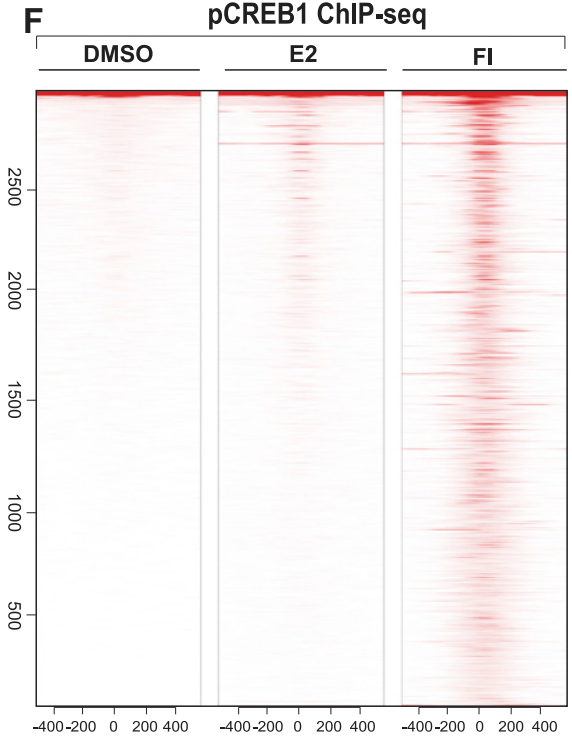

Figure 5. Genome-wide mapping of ER $\alpha$ and PCREB1 chromatin binding sites in response to E2 and cAMP.

(A, B) Average signals for the ChIP-seq datasets for ERa (A) and pCREB1 (B), obtained with MDA-MB-231 cells treated as indicated. The peak intensities are centered at the transcription factor peaks with a 2-kb window. (C, D) Venn diagrams of ERa (C) and pCREB1 (D) chromatinbinding sites as a function of treatment. Below the Venn diagrams, the number of sites (locations) that do not overlap between treatments are indicated. (E, F) Heat maps showing the ChIP-seq signals of ERa (E) and pCREB1 (F) in response to the indicated stimuli. Chromatin binding sites are sorted according to decreasing ChIP signals and centered at the respective transcription factor peaks with a 500-bp window on either side. 
A

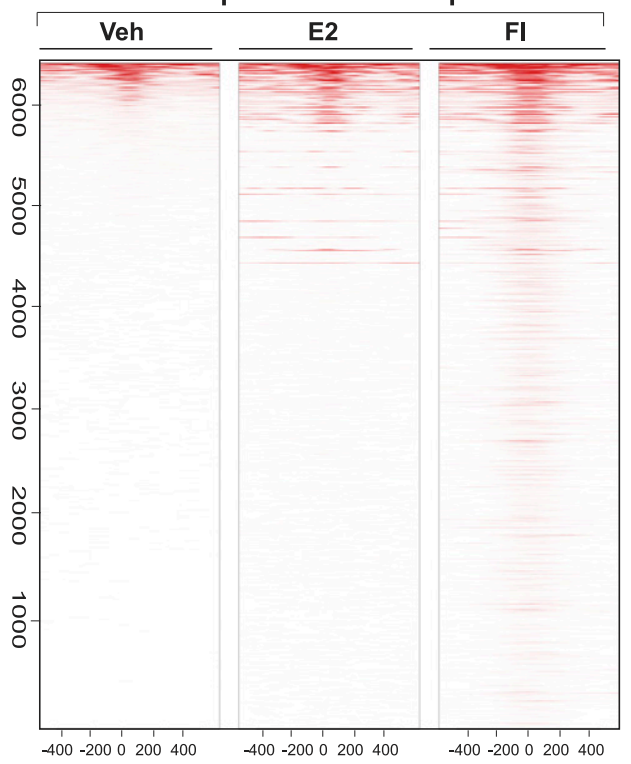

B

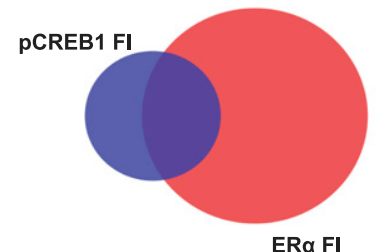

ER $\alpha$ FI only (7717 locations) pCREB1 FI only (1604 locations) ERa/pCREB1 1938 shared locations

C

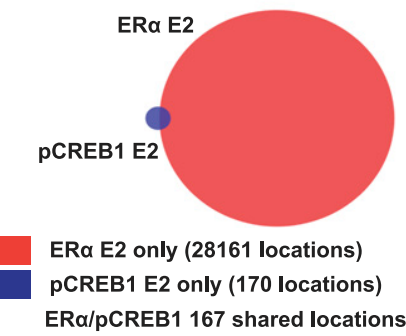

Figure 6 . Chromatin binding sites shared by pCREB1 and ER $\alpha$ are predominantly CAMP induced.

(A) Heat maps showing the ChIP-seq signals of pCREB1 over the ER $\alpha$ binding sites in response to the indicated stimuli. Regions are sorted according to decreasing signals in PCREB1 binding. Data are centered at the ER $\alpha$ peaks with a 500-bp window on either side. All data are from MDA-MB-134 cells. (B, C) Venn diagrams of the CAMP-induced sites (B) and the E2-induced sites (C) indicating those shared between ERa (red) and pCREB1 (blue). (D) Genomic distribution of the peaks shared between ER $\alpha$ and $p C R E B 1$ in response to the indicated treatments. (E) Snapshots from the ChIP-seq data for both ER $\alpha$ and $p C R E B 1$ peaks are shown across indicated genes for DMSO (blue), E2 (red), and FI (green). Genomic coordinates are indicated. The numbers in square brackets in each panel indicate the scale based on the numbers of reads.

D pCREB1 and ERa shared binding sites

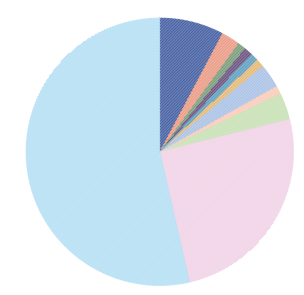

DMSO

Promoter (<=1000 bp): $7.8 \%$ Promoter $(1000-2000 \mathrm{bp}): 2.3 \%$ Promoter $(2000-3000 \mathrm{bp}): 0.8 \%$ Downstream (<=1000 bp): $1.0 \%$

Downstream (1000-2000 bp): $1.0 \%$ Downstream (2000-3000 bp): $0.8 \%$ 5'UTR: $2.9 \%$

3'UTR: $0.5 \%$

Coding exon: $3.3 \%$

Intron: $25.6 \%$

Distal intergenic: $\mathbf{5 4 . 1} \%$

E
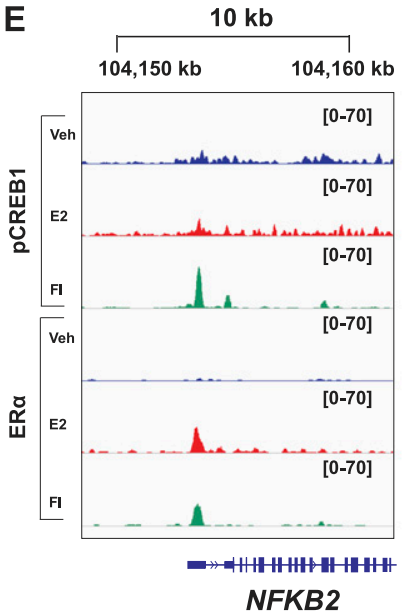

NFKB2

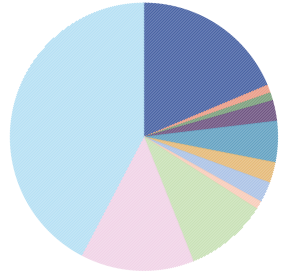

E2
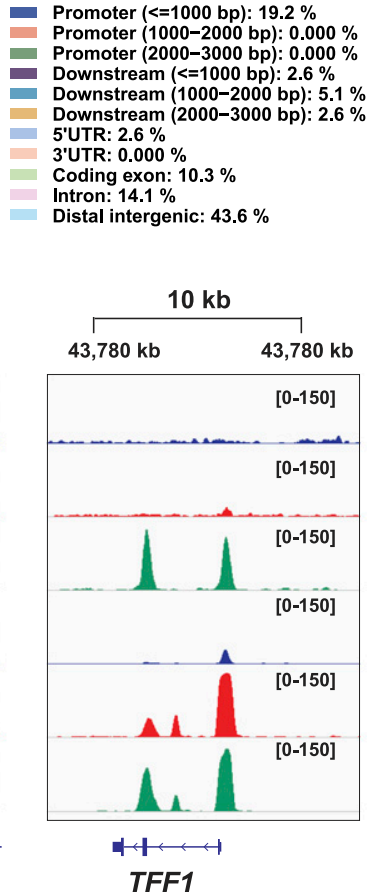

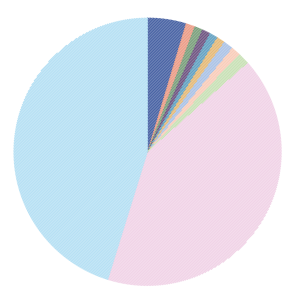

FI

Promoter $(<=1000 \mathrm{bp}): 4.7 \%$ Promoter $(1000-2000 \mathrm{bp}): 1.1 \%$ Downstream (<=1000 bp): $0.8 \%$ Downstream (1000-2000 bp): $0.8 \%$ Downstream (2000-3000 bp): $0.7 \%$ 5'UTR: $1.2 \%$ 3'UTR: $1.1 \%$ Coding exon: 1.5

Distal intergenic: $45.7 \%$

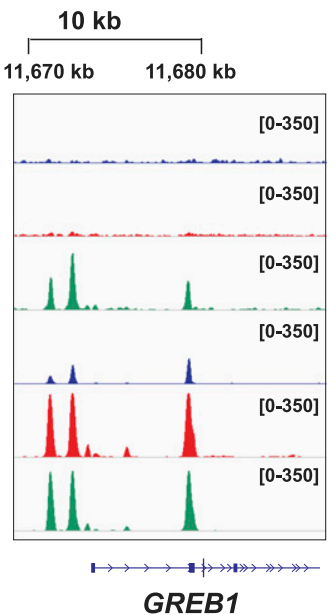


qPCR (Figs S6 and S7) and extended by monitoring the effects of overexpressing A-CREB1 or wild-type CREB1. For the same target sites and a few more shared ones, A-CREB and CREB1 clearly blocked and augmented pCREB1 recruitment, respectively (Fig S6).

In addition, we selected several genes that may be exclusively regulated by one or the other transcription factor based on our ChIP-seq data (Figs S7 and S8). For the genes ADCY9, RET, and ARHGEF26, which only showed sharp peaks for ERa, we could not find any binding events of PCREB1, irrespective of treatment, within a $20-60-k b$ window around the promoter region and/or gene. Complementary results were obtained by exploring the unique binding events of activated pCREB1: for the genes MRPL55, CCDC59, and RBM42, and unlike for the ER $\alpha$ target gene GREB1 included as a positive control, we could not find any ERa binding event within $50 \mathrm{~kb}$ of the promoter region (Figs S7 and S8). As could be predicted, the knockdown of CREB1 did not impair ERa binding to the unique ERa binding sites (Fig S7E).

Thus, it appears that ER $\alpha$ and CREB1 may primarily collaborate when their DNA-binding sites overlap or are nearby. Our immunoprecipitation experiments showed that the two transcription factors are part of a complex. Although we cannot exclude that they interact directly, it is likely that common coregulators with different interaction surfaces for the two might contribute to bringing them together. An obvious candidate for this is CBP/p300 (Kwok et al, 1994; Chakravarti et al, 1996; Webb et al, 1998). Indeed, when we overexpressed CBP, ER $\alpha$ recruitment was dramatically stimulated and further boosted by the co-overexpression of CREB1; the overexpression of the CREB1 mutant S133A abolished the stimulation by CBP (Fig S9).

The gene-specific regulatory environment may be a key parameter in determining whether ER $\alpha$ and CREB1 coordinately affect expression. Our transfected ERE-Luc reporter (Figs 1 and S2) may be a special case because ER $\alpha$ responses are clearly CREB1 dependent despite the apparent absence of a CREB1 response element. Although it lacks a canonical CREB1 binding site, notably a promoterproximal one, it contains many fortuitous CREB1 half sites throughout the plasmid. It is known that CREB1 half sites are in many instances sufficient for binding and transcriptional regulation (Mayr \& Montminy, 2001; Zhang et al, 2005). The particular topology of this transiently transfected and circular reporter gene may favor the assembly of a CBP/p300-stabilized ERA/CEBP1 complex as if it were controlled by a shared binding site.

Collectively, the genome-wide analysis provides a view of the complexity of the ER / pCREB1 crosstalk. Most chromatin binding events shared between these factors are CAMP responsive, suggesting that at the genome-wide level PCREB1 assists ER $\alpha$ activity principally in the absence of its cognate ligand and for a limited number of ERa target genes. Our results with CBP overexpression suggest that some of this synergy may be orchestrated by common coregulators.

\section{ER $\alpha$ and CREB1 contribute to protect breast cancer cells against apoptosis}

ERa is known to exert a protective role against apoptosis, in part by inducing the expression of anti-apoptotic genes such as BCL2 (Eguchi et al, 2000; Cericatto et al, 2005; Bratton et al, 2010). CREB1 plays a pro-survival role against induced death signals (Wilson et al, 1996; Finkbeiner, 2000; Shankar et al, 2005; Shukla et al, 2009; Schoknecht et al, 2017; Shabestari et al, 2017). Thus, ERa and CREB1 might collaborate to protect cells against apoptosis. To investigate this, we performed knockdowns of either ER $\alpha$ or CREB1 in MDA-MB134 cells (Fig S1B and C) and treated the cells with either E2 or CAMP for $24 \mathrm{~h}$ before subjecting them to an apoptotic stimulus. After the treatment with staurosporine (STS), we observed that the mitochondrial membrane potential is reduced, a marker of mitochondria-mediated cell death. We found that E2 and CAMP reduced mitochondrial depolarization (Fig S10A). Knocking down ER $\alpha$ or CREB1 suppressed this protective effect (Fig S10B and C), suggesting that the latter is mediated by ER $\alpha$ and CREB1. As a more direct assessment of apoptosis, we examined the effects of various treatments by determining the changes in nuclear morphology. This analysis confirmed what we had seen by looking at the mitochondrial membrane potential, which is a protective effect of ERo- and CREB1-mediated responses to E2 and CAMP (Fig 7A).

\section{CREB1 expression levels correlate with outcome in breast cancer}

To determine whether the expression level of CREB1 has any clinical significance, we mined outcome-linked gene expression data for breast cancer using the "Gene Expression-Based Outcome for Breast Cancer Online" (GOBO) tool (Ringnér et al, 2011) and displayed the outcomes in Kaplan-Meier curves. If one considers all types of ER $\alpha$-positive breast tumors, higher levels of CREB1 expression are significantly associated with better outcome, in this case improved "distant metastasis-free survival" (Fig 7B). For ER $\alpha$ positive tumors, this benefit of higher CREB1 levels disappears in the subset that is lymph node positive, and thus potentially more aggressive, and in those that are being treated with the antiestrogen tamoxifen, the standard endocrine therapy (Fig S11). The prognosis for ER $\alpha$-negative breast tumors is not affected by CREB1 levels in this dataset (Fig 7B). Although the GOBO database has a large number of breast cancer samples $(1,881)$, we decided to confirm these results by mining another database. Using the "Kaplan-Meier Plotter" (Lanczky et al, 2016), we interrogated "The Cancer Genome Atlas" (https://cancergenome.nih.gov). Although the numbers of samples for certain categories and analyses were lower than that with $\mathrm{GOBO}$, we found essentially the same results when we analyzed those that were comparable with both tools (Fig S12). Overall, these findings are consistent with the notion that a functional ERa/ CREB1 interplay is a positive predictor in breast cancer.

\section{Discussion}

Our study confirms and substantially complements the initial report (Lazennec et al, 2001) on a functional interaction between ERa and CREB1. Lazennec et al (2001) found that CREB1 stimulates ERa activity on a transfected reporter gene and that this can be blunted with a dominant-negative mutant of CREB1. Furthermore, they demonstrated an interaction with a mammalian two-hybrid assay. Here, we report that CREB1 and ER $\alpha$ can be biochemically shown to be part of the same complex and that CREB1 is required for ER $\alpha$ recruitment and responses. Our genome-wide analysis highlights 

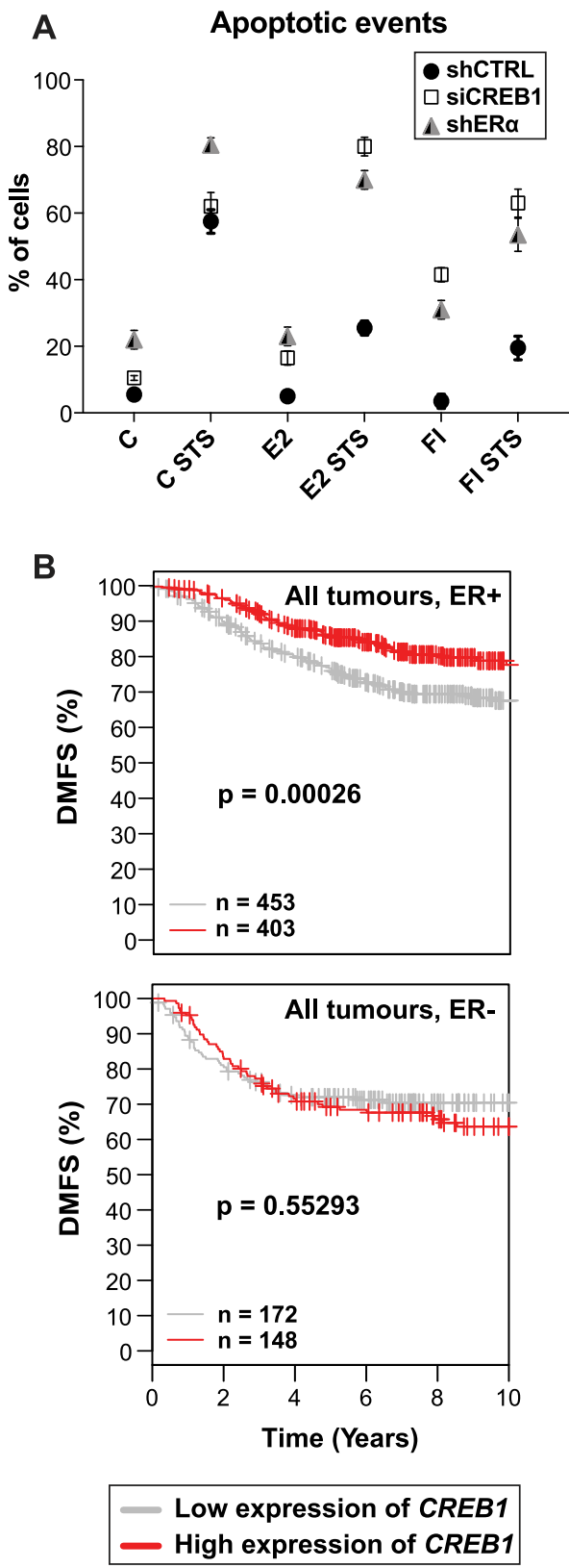

Figure 7. CREB1 and ER $\alpha$ differentially protect breast cancer cells and patients. (A) Both CREB1 and ERa suppress STS-induced apoptosis in response to E2 and CAMP. Knockdown of CREB1 and ERa, treatments with STS, E2, and Fl, and microscopic assessment of apoptosis were performed with MDA-MB-134 cells as described in the Materials and Methods section. The data points are averages of three independent experiments obtained by the inspection of 200 cells each, and the error bars indicate the standard error of the mean. (B) High expression levels of the CREB1 gene correlate with better breast cancer outcome. The CREB1 gene was used as a marker for the Kaplan-Meier analysis of breast cancers with the GOBO tool. The plots indicate distant metastasis-free survival (DMSF) as

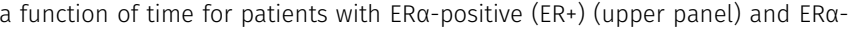
negative (ER-) (lower panel) breast cancers. Within each panel, the number of samples in each category and the $P$-value for the difference between high and low expression cases are shown. Additional analyses are presented in Figs S11 and S12.

the complex crosstalk between these two transcription factors and sets the stage for a better understanding of the biological synergy that may underlie the protective effects of both E2 and CAMP signaling against apoptosis and of high CREB1 levels in breast cancer patients.

\section{CREB1 stimulates and is required for ER $\alpha$ activity}

Our results demonstrate that CREB1 in its activated phosphorylated form stimulates ER $\alpha$ activity. CREB1 supports both the E2-activated liganded form and the CAMP-activated unliganded form of ER $\alpha$. Defective CREB1 mutants, including one that cannot be phosphorylated on a critical serine residue (S133A) and the CREB1 knockdown repress ERa activity. The latter finding argues that CREB1 itself is required in a non-redundant fashion despite the fact that it is only one member of a multiprotein family. Considering that CREB1 affects ER $\alpha$ activated either by cognate steroid ligand or through a ligand-independent pathway, we can argue that CREB1 acts downstream of the earliest steps in ER $\alpha$ activation, but upstream of ER $\alpha$ chromatin recruitment. This is supported by the ChIP and ChIP-seq experiments, which indicate that CREB1 promotes the recruitment of ER $\alpha$ to target sites, in particular to those that are shared between the two transcription factors. At least for these shared sites, CREB1 becomes a requirement for ER $\alpha$ recruitment and, as a consequence of that, of the transcriptional regulatory activity of $E R \alpha$ for the genes that are under the control of these sites. In fact, our results strongly argue that it is the phosphorylated version of CREB1, PCREB1, that is required. Upon CAMP signaling, the proportion of pCREB1 is expected to increase and it does (Fig 4). What exactly happens upon E2 signaling still needs to be clarified. Either the PCREB1 requirements are met by whatever basal level phosphorylated CREB1 there is, or there is a transient increase, which we have failed to see in our experiments (Fig 4), in response to the non-genomic stimulation of adenylate cyclase activity by E2 (Aronica et al, 1994; Levin \& Hammes, 2016; Barton et al, 2018). Because ER $\alpha$ is a target of PKA as well (Anbalagan \& Rowan, 2015), one must wonder whether its phosphorylation plays any role in the synergy described here. Although we have not directly addressed this issue in this context, the first report on ERa/CREB1 synergy came to the conclusion that it is not (Lazennec et al, 2001), and we found that an ER $\alpha$ mutant that cannot be phosphorylated on S305, the main PKA target site, is still activated by cAMP (Carascossa et al, 2010).

It is remarkable that CREB1 is also needed for the ligandindependent activation of ER $\alpha$ by CAMP signaling. Overall, we now know of three factors that are required and are targets of PKA. Upon phosphorylation by PKA, CARM1 can directly interact with the $\mathrm{ER} \alpha \mathrm{HBD}$ in the absence of estrogen (Carascossa et al, 2010), possibly promoting the recruitment of yet other factors. The deacetylase LSD1 may be one of them, because its phosphorylation by PKA and recruitment to ER $\alpha$ are necessary for ER $\alpha$ activity (Bennesch et al, 2016). pCREB1 is the third factor that we have found to be needed to relay the CAMP signal and to promote the activation of ER $\alpha$. At this point, we do not know the exact order of events nor can we exclude that the phosphorylation and recruitment of yet other factors may be needed. It should be pointed out that this mode of activation of ER $\alpha$ still requires an active AF2 and presumably many of the factors that associate with it (Carascossa et al, 2010). The phosphorylation of multiple factors by PKA might promote the assembly of a multiprotein complex on the ER $\mathrm{HBD}$, which ultimately favors the conformational change of the HBD 
converting AF2 into its active state, even in the absence of the estrogenic ligand, which normally triggers this transition.

\section{Molecular mechanism of transcription factor synergy}

The key question is how the synergy of ER $\alpha$ and CREB1 comes about at the molecular level. Several possibilities are conceivable: (i) Both transcription factors contact specific response elements; for shared chromatin binding sites, they may be sufficiently close to allow the interaction between ER $\alpha$ and CREB1 to favor and to stabilize target site engagement; the interaction may be indirect and/or strengthened by shared coregulators such as CBP/p300, and it might occur over larger distances by looping. (ii) Only one of the two directly binds DNA whereas the other tethers to it. ERa is well known to be able to tether to AP-1, NF-KB, and CREB1 (Heldring et al, 2007, 2011). Interestingly, a DNA-binding defective CREB1 mutant prevents ER $\alpha$ from tethering not only onto DNA-bound CREB1 but also onto AP-1 (Heldring et al, 2011). This indicates that CREB1 is more generally required for $E R \alpha$ function through tethering. (iii) One acts as the pioneer factor for the other. Pioneer factors are a particular class of transcription factors, which can bind compacted chromatin. Once they have initiated chromatin remodeling, the DNA becomes more accessible for "standard" transcription factors. This concept has been extensively elaborated for $E R \alpha$, for which various factors such as FoxA1 act as pioneer factors (Jozwik \& Carroll, 2012). However, the distinction between pioneer factors and transcription factors does not sufficiently take into account the dynamic aspects of chromatin interactions. An alternative and complementary view posits that the boundaries between pioneer factors and transcription factors may be somewhat arbitrary (Voss et al, 2011; Swinstead et al, 2016b). Through assisted loading, one transcription factor, for example the GR, may promote the activity of another one such as ERa (Voss et al, 2011).

Several of these mechanisms may be involved in the ERa/CREB1 crosstalk, which we have described here. A sequence motif analysis for the shared binding sites supports the idea that multiple mechanisms might be at work (Fig S13). Not surprisingly, the most common sequence motifs in ER $\alpha$ and CREB1 binding sites, irrespective of treatment, correspond to canonical EREs and CREs (Fig S13A). Whereas a substantial proportion of the nearly 2,000 shared binding sites in response to CAMP (Fig 6B) contain EREs and/or CRES (Fig S13B), only a minority of the 167 sites in response to E2 (Fig 6C) do so (Fig S13B). Clearly, only an in-depth analysis of individual target sites will allow one to discriminate between different mechanisms. For many of the ERa target sites we have focused on, a direct contact of ER $\alpha$ with the DNA is known to be involved. For CREB1, direct DNA binding must be involved at least for all those cases where we showed that the overexpression of a DNA-binding defective mutant blocks ER $\alpha$ activity. Regarding the DNA-binding requirement, this situation is reminiscent of the E2- and TNFainduced crosstalk between ER $\alpha$ and NF-KB. In this case, the concomitant activation of NF-KB redirects ER $\alpha$ to shared sites (Franco et $\mathrm{al}, 2015)$. At a genome-wide level, discriminating between different modes of action, as outlined above, may be somewhat semantic because the assembly of large regulatory structures, such as those previously termed superenhancers or MegaTrans enhancers (Hnisz et al, 2013; Liu et al, 2014), provides a complex framework for concomitant yet dynamic interactions between multiple transcription factors, coregulators, DNA, and chromatin components.

\section{Physiological relevance of ER /CREB1 synergy}

ER $\alpha$ and CREB1 have long been known, separately, to be protective factors against apoptosis (Wilson et al, 1996; Eguchi et al, 2000; Finkbeiner, 2000; Cericatto et al, 2005; Shankar et al, 2005; Shukla et al, 2009; Bratton et al, 2010; Schoknecht et al, 2017; Shabestari et al, 2017). This correlates with their ability to induce directly the expression of anti-apoptotic genes such as BCL2. We have confirmed with MDA-MB-134 breast cancer cells that both E2 and CAMP signaling protect cells against an apoptotic stimulus. The protective effect of these signals is mediated by ER $\alpha$ and CREB1 because their knockdown sensitizes cells (Figs 7A and S10). The BCL2 gene is likely to be an important target, but considering the large size of the ER $\alpha$ and CREB1 cistromes, including the shared sites, there may be many more relevant target genes. To gain a better understanding of how ER $\alpha$ and CREB1 act to protect cells, these genes will have to be identified. Moreover, their in-depth analysis should allow one to determine whether they are regulated independently by ER $\alpha$ and CREB1 or whether they are subject to the synergistic regulation described here.

Our analysis of publicly available gene expression profiles revealed that high levels of CREB1 are associated with better prognosis in ER $\alpha$ positive breast cancers, i.e., that they must have a protective effect in patients as well, and not just in cells. At first, it may seem paradoxical that protecting breast cancer cells against apoptosis at the cellular level may translate into a beneficial effect in patients. However, this might be resolved by the fact that a functional ER $\alpha$ is associated with better prognosis in breast cancer. Being required for ER $\alpha$ function, high levels of CREB1 may contribute to prevent a tumorigenic evolution, notably for cancers that have not yet been treated with tamoxifen, toward more aggressive and therapy-resistant versions of breast cancer that are estrogen and ER independent.

\section{Materials and Methods}

\section{Antibodies and reagents}

The rabbit polyclonal antisera HC-20 and A300-498-A against ER $\alpha$ were purchased from Santa Cruz Biotechnology and Bethyl Laboratories, respectively; the rabbit polyclonal antiserum A300-421A against CARM1 was purchased from Bethyl Laboratories; the rabbit monoclonal antibodies against pCREB1 (87G3) and CREB1 $(48 \mathrm{H} 2)$ were purchased from Cell signaling Technology; the mouse monoclonal antibody against the tag HA.11 (clone 16B12) was purchased from BioLegend; the mouse monoclonal antibodies against the FLAG tag (clone M2) and $\alpha$-tubulin (T9026) were purchased from Sigma-Aldrich; the mouse monoclonal antibody against GAPDH (6C5) was purchased from Abcam. Corresponding control IgGs from rabbit (Cat. No. 15006) and mouse (15381) were purchased from Sigma-Aldrich.

$17 \beta$-estradiol (E2) was purchased from Sigma-Aldrich, forskolin and STS from Chemie-Brunschwig, and 3-isobutyl-1-methylxanthine from Millipore. All reagents were dissolved in DMSO as vehicle. 


\section{Plasmids}

The empty expression vector pCMV4 was from Addgene. The following series of expression vectors based on plasmid pCMV5-HA were obtained through the "MRC PPU Reagents and Services Facility" at the University of Dundee: pCMV5-HA CREB1 (\# DU4071), pCMV5-HA CREB1 S133A (\# DU4073), and pCMV5-HA CREB1 S133D (\# DU4106). The expression vectors pCMV-FLAG A-CREB1 (Ahn et al, 1998), pRC/RSV-mCBP-HA (Chrivia et al, 1993), and HEG0 for wildtype ERa (Tora et al, 1989) have been described.

For luciferase reporter assays, the following plasmids were used: the luciferase reporters XETL (here referred to as ERE-LUC) for ER $\alpha$ (Bunone et al, 1996), CRE-Luc for CREB1 (Stratagene), XTL (here referred to as Luc) without response element (Bunone et al, 1996) as a negative control, and plasmid GK1 for the Gal4 fusions (Webb et al, 1998). The Renilla luciferase pRL-CMV (Promega) was used as transfection control. The expression vector series pSCTEV gal93 was used for expression of the Gal4 DNA-binding domain (aa 1-93) fusions (Seipel et al, 1992) with the ER $\alpha$ HBD and AF2 (aa 282-595) (Maggiolini et al, 2001), the $\mathrm{N}$-terminal domain of ERa with the activation function AF1 (aa 82-152) (Gburcik et al, 2005), the ER $\alpha$ DNA-binding domain (aa 180-262) (Carascossa et al, 2010), and the ERa hinge region (aa 251-300) (Carascossa et al, 2010). The expression vector for Gal4 fusion with full-length CREB1 was a gift from Ugo Moens (Delghandi et al, 2005).

For the knockdown of ERa, cells were infected with pLKO.1-based lentiviruses expressing either a specific shRNA against ERa (from construct pLKO.shESR1) (Bennesch et al, 2016) or against CREB1 (Table S1) or scrambled shRNA as control (from construct pLKO. shCTRL) (Sarbassov et al, 2005). The plasmids psPAX2 and PMD2G (gift from Didier Trono's laboratory at EPFL) were used for preparing the lentiviruses.

\section{Cell culture and transfection experiments}

HEK293T, MDA-MB-134, and MCF7 cells were maintained in Dulbecco's modified Eagle's medium supplemented with 10\% FBS and $1 \%$ penicillin-streptomycin $(\mathrm{P} / \mathrm{S})$. Before transfection experiments, cells were cultured for $3 \mathrm{~d}$ in phenol red-free medium, supplemented with $5 \%$ charcoal-stripped FBS (5\% ch-FBS), 1\% P/S, and 1\% L-glutamine. Except for siRNA experiments, transient transfections of different plasmid constructs were performed with polyethylenimine MAX 4000 (Polysciences) for $24 \mathrm{~h}$ in serum- and P/Sfree medium supplemented with glutamine. Subsequently, after replacing this medium with fresh phenol red- and serum-free medium, the cells were treated with the vehicle DMSO, $100 \mathrm{nM}$ $\mathrm{E} 2$, or the cocktail $\mathrm{FI}$ (consisting of $10 \mu \mathrm{M}$ forskolin and $100 \mu \mathrm{M}$ 3-isobutyl-1-methylxanthine) for 1, 6, and $24 \mathrm{~h}$ before harvesting for ChIP and immunoprecipitation, RT-PCR, and luciferase assays, respectively.

\section{shRNA- and siRNA-mediated knockdowns}

For the production of lentiviruses, HEK293T cells were seeded to a $60 \%$ confluency in medium $24 \mathrm{~h}$ before polyethylenimine transfection in complete medium with plasmids pLKO.shESR1, pLKO. shCREB1, or pLKO.shCTRL plus plasmids PMD2G and pSPAX2. $24 \mathrm{~h}$ later, the medium was replaced with fresh complete medium and lentivirus-containing supernatants were collected every $12 \mathrm{~h}$ during $48 \mathrm{~h}$. These supernatants were used to infect MDA-MB-134 or MCF7 cells during $72 \mathrm{~h}$. After infection, cells were subjected to selection with $3 \mu \mathrm{g} / \mathrm{ml}$ puromycin for at least $24 \mathrm{~h}$ to eliminate any remaining non-infected cells. After selection, cells were collected for experiments or maintained in normal culture medium, with $1 \mu \mathrm{g} / \mathrm{ml}$ of puromycin, for not more than a week. The efficiency of the knockdown was tested each time by immunoblotting. For siCREB1mediated knockdowns, MDA-MB-134 cells were transfected with a final concentration of $20 \mathrm{nM}$ siRNA, purchased as a pool of four individual siRNAs targeting CREB1 (ON-TARGETplus Human CREB1 SIRNA) and a pool of four siRNAs designed as negative control (ONTARGETplus Non-targeting Pool siRNA) from Dharmacon. Where indicated, siRNAs were cotransfected with plasmid DNAs; transfections were performed using Jet-Prime (PolyPlus) in medium without serum and $\mathrm{P} / \mathrm{S}$, supplemented with glutamine for $4 \mathrm{~h}$. After infection and selection, or siRNA/plasmid transfection, the medium was replaced with phenol red-and serum-free medium, and the cells were incubated for $24 \mathrm{~h}$ before performing experiments (such as inducing cells for $24 \mathrm{~h}$ for luciferase or apoptosis assays).

\section{Immunoprecipitation experiments}

Cells were washed once with ice-cold PBS and lysed with a buffer containing $10 \mathrm{mM}$ Tris- $\mathrm{HCl}$, pH 7.5, 50 mM NaCl, 1 mM EDTA, 1 mM DTT, $10 \%$ glycerol, $10 \mathrm{mM}$ Na-molybdate, and a protease inhibitor cocktail (Thermo Fisher Scientific). Cells were broken by sonication with 40 on/off cycles of $30 \mathrm{~s}$ at high power using the Bioruptor sonicator (Diagenode). After that, cell lysates were centrifuged at maximal speed at $4^{\circ} \mathrm{C}$ for $10 \mathrm{~min}$. Supernatants were recovered whereas pellets containing the cell debris were discarded. Protein concentrations of lysates were measured using the Bradford protein assay. $100 \mu \mathrm{g}$ proteins were saved for input and $2 \mathrm{mg}$ were incubated with protein G-dynabeads (Life Technologies) precoated with specific antibody or with control antibody of the same species by overnight rotation at $4^{\circ} \mathrm{C}$. Beads were washed $4 \times$, 10 min each, with lysis buffer containing $0.1 \%$ Triton $X-100$, and then boiled in sample buffer containing 100 mM DTT.

\section{Extraction of total cellular protein for immunoblotting}

Cells were washed once and pelleted with ice-cold Tris-buffered saline. Cells were lysed in cold RIPA lysis buffer $(50 \mathrm{mM}$ Tris- $\mathrm{HCl}$, pH 7.4, 150 mM NaCl, 1\% Triton X-100, 10\% glycerol, 1 mM EDTA, and $1 \mathrm{mM}$ DTT) supplemented with a protease inhibitor cocktail (Thermo Fisher Scientific), and sonicated $15 \times$ for $30 \mathrm{~s}$ at high power using the Bioruptor sonicator (Diagenode). Lysates were centrifuged at maximum speed, at $4^{\circ} \mathrm{C}$, and for $30 \mathrm{~min}$. Supernatants were recovered and cell debris was discarded. Protein concentrations of lysates were measured using the Bradford protein assay.

\section{Luciferase activity assays}

Firefly luciferase and Renilla luciferase control activities were measured using the Dual-Luciferase Reporter Assay System (Promega), following the manufacturer's instructions. For each 
condition, firefly luminescence is standardized to the activity of the Renilla luciferase transfection control. Values are expressed as fold increase relative to the DMSO-treatment conditions, arbitrarily set to 1 .

\section{Gene expression analyses by quantitative RT-PCR}

RNA extraction for RT-PCR was performed with MDA-MB-134 cells following the previously described protocol (Bennesch et al, 2016). The specific primers are listed in Table S2. mRNA levels were standardized to the mRNA of the internal housekeeping gene GAPDH, and expressed as fold increase relative to the DMSOtreatment conditions, arbitrarily set to 1.

\section{ChIP-qPCR}

Cross-linking and lysis of cells for ChIP were performed following a previously published protocol (Schmidt et al, 2009). Recruitment of ER $\alpha$ or pCREB1 was determined by using GPCR, using specific primers and primers to a region of the FGFR9 gene as negative control. Primer sequences are listed in Table S3. Values of each target region were normalized to their corresponding input values and then to the values of the negative control region. Recruitment is presented as the fold recruitment relative to DMSO-treated cells.

\section{ChIP-seq}

ChIP-seq samples were generated from two biological replicates for each condition with the rabbit polyclonal antiserum A300-498-A against ER $\alpha$ and the rabbit monoclonal $87 G 3$ against pCREB1. A total of $5 \mathrm{ng}$ of recovered DNA was used to generate libraries for sequencing, following a previously published protocol (Schmidt et al, 2009). Sequencing adaptors were attached applying the Illumina TruSeq protocol and sequenced using an Illumina HiSeq 2500 sequencer. Analyses were done with tools of the Galaxy suite (https:/ / usegalaxy.org). ChIP-seq libraries were aligned to the reference genome hg19 using default parameters of Bowtie 2 alignment (version 2.2.6). The enriched regions of the genome were identified by comparing sequences from treated samples to those of the IgG control sample using the MACS peak caller (version 2.1.1.20160309.0). Venn diagram (version 1.0.0), HeatMap (version 1.0.0), SitePro aggregation plots (version 1.0.0), and "Enrichment on chromosome and annotation" (CEAS, version 1.0.0) analyses were performed using the online Galaxy/Cistrome tool. Examples of shared chromatin interactions of pCREB1 and ER $\alpha$ were displayed using the Integrative Genomic Viewer (IGV_version 2.3.97). The criterion for calling peaks "shared" was a minimal overlap of the reads by at least $1 \mathrm{bp}$ in both replicates. Motif analyses were performed using the MEME (version 4.11.1.0) and FIMO (version 4.11.10) (Grant et al, 2011) tools of the MEME suite (http://meme-suite.org) (Bailey \& Elkan, 1994).

\section{Assay of mitochondrial membrane potential}

MDA-MB-134 cells, cultured in preparation of the experiment as indicated above, were stimulated with E2, Fl, or DMSO for $24 \mathrm{~h}$ and apoptosis was triggered with $1 \mu \mathrm{M}$ STS during the last $4 \mathrm{~h}$ of each treatment. Cells were washed twice with PBS, detached by trypsinization, harvested, resuspended in $200 \mu \mathrm{l}$ PBS, and transferred to a 5-ml FACS tube. 200 nM MitoTracker Red (Thermo Fisher Scientific) was added and the assay tubes were incubated at $37^{\circ} \mathrm{C}$ for $30 \mathrm{~min}$. Before analyses by flow cytometry, another $200 \mu \mathrm{l}$ PBS was added to each tube. The analyses of a set number of cells $(10,000)$ were performed with a FACSCalibur cell analyzer (BD Biosciences) and the software CellQuest Pro; the acquired data were processed with the software Flowjo.

\section{Fluorescence microscopy for apoptotic events}

MDA-MB-134 cells were cultured and treated as mentioned above, and then fixed in $4 \% \mathrm{wt} / \mathrm{vol}$ paraformaldehyde for $10 \mathrm{~min}$ and washed in ice-cold PBS. PBS containing $0.5 \% \mathrm{wt} / \mathrm{vol}$ bovine serum albumin and $0.01 \%$ of Triton X-100 was added for 30 min to permeabilize cell membranes. Cells were washed twice with cold PBS, gently rocking, and the blocking solution containing $5 \% \mathrm{wt} / \mathrm{vol}$ bovine serum albumin in PBS was added for $1 \mathrm{~h}$ at room temperature. Cell nuclei were stained with a solution containing DAPI in PBS for 30 min. Coverslips were mounted face down and pictures were acquired by microscopy using a ZEISS Axiophot. Apoptotic cells were identified based on their nuclear morphology as described (Cummings et al, 2012); Briefly, cells characterized by a strong nuclear condensation or with chromatin clustered at the edge or periphery of the nuclear membrane were classified as apoptotic cells. For each condition, more than 200 cells were counted and the number of apoptotic cells was expressed as a percentage of the total.

\section{Kaplan-Meier curves}

Kaplan-Meier curves (Dinse \& Lagakos, 1982) were generated using the online tools GOBO (http://co.bmc.lu.se/gobo) (Ringnér et al, 2011) and "Kaplan-Meier Plotter" (http:// kmplot.com/analysis) (Lanczky et al, 2016) with CREB1 as the query gene (Entrez gene ID: 1385 and gene ID: 22572_at, respectively). Note that "Kaplan-Meier Plotter" can interrogate several databases, including The Cancer Genome Atlas.

\section{Statistical analyses}

Unless otherwise indicated, the data shown are representative of three independent biological experiments with triplicate samples in the case of luciferase assays and technical replicates for ChIPqPCR and RT-PCR analyses, with error bars indicating the standard deviation of the mean. For some relevant comparisons, $t$ tests were performed.

\section{Data availability}

ChIP-seq data have been deposited in the GEO repository under the series record GSE109103.

\section{Supplementary Information}

Supplementary Information is available at https://doi.org/10.26508/lsa. 201800055 


\section{Acknowledgements}

We thank the genomics platform of iGE3 for sequencing of the ChIP-seq samples of ER $\alpha$ and pCREB1, Federico Miozzo and Grégory Ségala for advice and help with the online Galaxy platform, and Suzan Stelloo for initial training for ChIP experiments. We are also grateful to Grégory Ségala for critical reading of the manuscript. This work was supported by the Swiss National Science Foundation, the Medic foundation, and the Canton de Genève.

\section{Author Contributions}

M Berto: conceptualization, formal analysis, investigation, and writing-original draft, review, and editing.

$\checkmark$ Jean: writing-review and editing and performed preliminary experiments.

W Zwart: conceptualization and writing-review and editing, and analysis of preliminary results.

D Picard: conceptualization, formal analysis, supervision, funding acquisition, writing-original draft, project administration, and writing-review and editing.

\section{Conflict of Interest Statement}

The authors declare that they have no conflict of interest.

\section{References}

Ahn S, Olive M, Aggarwal S, Krylov D, Ginty DD, Vinson C (1998) A dominantnegative inhibitor of CREB reveals that it is a general mediator of stimulus-dependent transcription of c-fos. Mol Cell Biol 18: 967-977. doi:10.1128/mcb.18.2.967

Akerblom IE, Slater EP, Beato M, Baxter JD, Mellon PL (1988) Negative regulation by glucocorticoids through interference with a CAMP responsive enhancer. Science 241: 350-353. doi:10.1126/science. 2838908

Anbalagan M, Rowan BG (2015) Estrogen receptor a phosphorylation and its functional impact in human breast cancer. Mol Cell Endocrinol 418: 264-272. doi:10.1016/j.mce.2015.01.016

Aronica SM, Katzenellenbogen BS (1993) Stimulation of estrogen receptormediated transcription and alteration in the phosphorylation state of the rat uterine estrogen receptor by estrogen, cyclic adenosine monophosphate, and insulin-like growth factor-I. Mol Endocrinol 7: 743-752. doi:10.1210/me.7.6.743

Aronica SM, Kraus WL, Katzenellenbogen BS (1994) Estrogen action via the CAMP signaling pathway: Stimulation of adenylate cyclase and CAMPregulated gene transcription. Proc Natl Acad Sci USA 91: 8517-8521. doi:10.1073/pnas.91.18.8517

Bailey TL, Elkan C (1994) Fitting a mixture model by expectation maximization to discover motifs in biopolymers. Proc Int Conf Intell Syst Mol Biol 2: 28-36.

Barton M, Filardo EJ, Lolait SJ, Thomas P, Maggiolini M, Prossnitz ER (2018) Twenty years of the G protein-coupled estrogen receptor GPER: Historical and personal perspectives. J Steroid Biochem Mol Biol 176: 4-15. doi:10.1016/j.jsbmb.2017.03.021

Bennesch MA, Picard D (2015) Tipping the balance: Ligand-independent activation of steroid receptors. Mol Endocrinol 29: 349-363. doi:10.1210/me.2014-1315
Bennesch MA, Segala G, Wider D, Picard D (2016) LSD1 engages a corepressor complex for the activation of the estrogen receptor $\alpha$ by estrogen and CAMP. Nucleic Acids Res 44: 8655-8670. doi:10.1093/nar/gkw522

Bratton MR, Duong BN, Elliott S, Weldon CB, Beckman BS, McLachlan JA, Burow ME (2010) Regulation of ER $\alpha$-mediated transcription of Bcl-2 by PI3K-AKT crosstalk: Implications for breast cancer cell survival. Int J Oncol 37: 541-550. doi:10.3892/ijo_00000703

Bunone G, Briand PA, Miksicek RJ, Picard D (1996) Activation of the unliganded estrogen receptor by EGF involves the MAP kinase pathway and direct phosphorylation. EMBO J 15: 2174-2183.

Carascossa S, Dudek P, Cenni B, Briand PA, Picard D (2010) CARM1 mediates the ligand-independent and tamoxifen-resistant activation of the estrogen receptor $\alpha$ by cAMP. Genes Dev 24: 708-719. doi:10.1101/ gad. 568410

Cericatto R, Pozzobon A, Morsch DM, Menke CH, Brum IS, Spritzer PM (2005) Estrogen receptor- $\alpha, b c l-2$ and c-myc gene expression in fibroadenomas and adjacent normal breast: Association with nodule size, hormonal and reproductive features. Steroids 70: 153-160. doi:10.1016/j.steroids.2004.10.013

Chakravarti D, LaMorte VJ, Nelson MC, Nakajima T, Schulman IG, Juguilon H, Montminy M, Evans RM (1996) Role of CBP/P300 in nuclear receptor signalling. Nature 383: 99-103. doi:10.1038/383099a0

Chen D, Huang SM, Stallcup MR (2000) Synergistic, p160 coactivatordependent enhancement of estrogen receptor function by CARM1 and p300. J Biol Chem 275: 40810-40816. doi:10.1074/jbc.m005459200

Chrivia JC, Kwok RP, Lamb N, Hagiwara M, Montminy MR, Goodman RH (1993) Phosphorylated CREB binds specifically to the nuclear protein CBP. Nature 365: 855-859. doi:10.1038/365855a0

Cummings BS, Wills LP, Schnellmann RG (2012) Measurement of cell death in mammalian cells. Curr Protoc Pharmacol 56: 12.18.11-12.18.24. doi:10.1002/0471141755.ph1208s56

de Leeuw R, Flach K, Bentin Toaldo C, Alexi X, Canisius S, Neefjes J, Michalides R, Zwart W (2013) PKA phosphorylation redirects ER a to promoters of a unique gene set to induce tamoxifen resistance. Oncogene 32: 3543-3551. doi:10.1038/onc.2012.361

Delghandi MP, Johannessen M, Moens U (2005) The CAMP signalling pathway activates CREB through PKA, p38 and MSK1 in NIH 3T3 cells. Cell Signal 17: 1343-1351. doi:10.1016/j.cellsig.2005.02.003

Diaz-Gallardo MY, Cote-Velez A, Carreon-Rodriguez A, Charli JL, Joseph-Bravo P (2010) Phosphorylated cyclic-AMP-response element-binding protein and thyroid hormone receptor have independent response elements in the rat thyrotropin-releasing hormone promoter: An analysis in hypothalamic cells. Neuroendocrinology 91: 64-76. doi:10.1159/000228833

Dinse GE, Lagakos SW (1982) Nonparametric estimation of lifetime and disease onset distributions from incomplete observations. Biometrics 38: 921-932. doi:10.2307/2529872

Dudek P, Picard D (2008) Genomics of signaling crosstalk of estrogen receptor $\alpha$ in breast cancer cells. PLoS One 3: e1859. doi:10.1371/ journal.pone.0001859

Eguchi H, Suga K, Saji H, Toi M, Nakachi K, Hayashi SI (2000) Different expression patterns of $\mathrm{Bcl}-2$ family genes in breast cancer by estrogen receptor status with special reference to proapoptotic Bak gene. Cell Death Differ 7: 439-446. doi:10.1038/sj. cdd. 4400675

Finkbeiner S (2000) CREB couples neurotrophin signals to survival messages. Neuron 25: 11-14. doi:10.1016/s0896-6273(00)80866-1

Flach KD, Zwart W (2016) The first decade of estrogen receptor cistromics in breast cancer. J Endocrinol 229: R43-R56. doi:10.1530/joe-16-0003

Franco HL, Nagari A, Kraus WL (2015) TNFa signaling exposes latent estrogen receptor binding sites to alter the breast cancer cell transcriptome. Mol Cell 58: 21-34. doi:10.1016/j.molcel.2015.02.001 
Gburcik V, Bot N, Maggiolini M, Picard D (2005) SPBP is a phosphoserinespecific repressor of estrogen receptor $\alpha$. Mol Cell Biol 25: 3421-3430. doi:10.1128/mcb.25.9.3421-3430.2005

Grant CE, Bailey TL, Noble WS (2011) FIMO: Scanning for occurrences of a given motif. Bioinformatics 27: 1017-1018. doi:10.1093/ bioinformatics/btr064

Heldring N, Isaacs GD, Diehl AG, Sun M, Cheung E, Ranish JA, Kraus WL (2011) Multiple sequence-specific DNA-binding proteins mediate estrogen receptor signaling through a tethering pathway. Mol Endocrinol 25: 564-574. doi:10.1210/me.2010-0425

Heldring N, Pike A, Andersson S, Matthews J, Cheng G, Hartman J, Tujague M, Strom A, Treuter E, Warner M, et al (2007) Estrogen receptors: How do they signal and what are their targets. Physiol Rev 87: 905-931. doi:10.1152/physrev.00026.2006

Hnisz D, Abraham BJ, Lee TI, Lau A, Saint-Andre V, Sigova AA, Hoke HA, Young RA (2013) Super-enhancers in the control of cell identity and disease. Cell 155: 934-947. doi:10.1016/j.cell.2013.09.053

Hua S, Kittler R, White KP (2009) Genomic antagonism between retinoic acid and estrogen signaling in breast cancer. Cell 137: 1259-1271. doi:10.1016/j.cell.2009.04.043

Jozwik KM, Carroll JS (2012) Pioneer factors in hormone-dependent cancers. Nat Rev Cancer 12: 381-385. doi:10.1038/nrc3263

Kalaitzidis D, Gilmore TD (2005) Transcription factor cross-talk: The estrogen receptor and NF-KB. Trends Endocrinol Metab 16: 46-52. doi:10.1016/j. tem.2005.01.004

Kushner PJ, Agard DA, Greene GL, Scanlan TS, Shiau AK, Uht RM, Webb P (2000) Estrogen receptor pathways to AP-1. J Steroid Biochem Mol Biol 74: 311-317. doi:10.1016/s0960-0760(00)00108-4

Kwok RP, Lundblad JR, Chrivia JC, Richards JP, Bachinger HP, Brennan RG, Roberts SG, Green MR, Goodman RH (1994) Nuclear protein CBP is a coactivator for the transcription factor CREB. Nature 370: 223-226. doi:10.1038/370223a0

Lanczky A, Nagy A, Bottai G, Munkacsy G, Szabo A, Santarpia L, Gyorffy B (2016) miRpower: A web-tool to validate survival-associated miRNAs utilizing expression data from 2178 breast cancer patients. Breast Cancer Res Treat 160: 439-446. doi:10.1007/s10549-016-4013-7

Lazennec G, Thomas JA, Katzenellenbogen BS (2001) Involvement of cyclic AMP response element binding protein (CREB) and estrogen receptor phosphorylation in the synergistic activation of the estrogen receptor by estradiol and protein kinase activators. J Steroid Biochem Mol Biol 77: 193-203. doi:10.1016/s0960-0760(01) 00060-7

Lee YH, Coonrod SA, Kraus WL, Jelinek MA, Stallcup MR (2005) Regulation of coactivator complex assembly and function by protein arginine methylation and demethylimination. Proc Natl Acad Sci USA 102: 3611-3616. doi:10.1073/pnas.0407159102

Levin ER, Hammes SR (2016) Nuclear receptors outside the nucleus: Extranuclear signalling by steroid receptors. Nat Rev Mol Cell Biol 17: 783-797. doi:10.1038/nrm.2016.122

Liu Z, Merkurjev D, Yang F, Li W, Oh S, Friedman MJ, Song X, Zhang F, Ma Q, Ohgi KA, et al (2014) Enhancer activation requires trans-recruitment of a mega transcription factor complex. Cell 159: 358-373. doi:10.1016/j. cell.2014.08.027

Maggiolini M, Bonofiglio D, Marsico S, Panno ML, Cenni B, Picard D, Ando S (2001) Estrogen receptor $\alpha$ mediates the proliferative but not the cytotoxic dose-dependent effects of two major phytoestrogens on human breast cancer cells. Mol Pharmacol 60: 595-602.

Mayr B, Montminy M (2001) Transcriptional regulation by the phosphorylation-dependent factor CREB. Nat Rev Mol Cell Biol 2: 599-609. doi:10.1038/35085068

Power RF, Mani SK, Codina J, Conneely OM, O'Malley BW (1991) Dopaminergic and ligand-independent activation of steroid hormone receptors. Science 254: 1636-1639. doi:10.1126/science.1749936
Ratman D, Vanden Berghe W, Dejager L, Libert C, Tavernier J, Beck IM, De Bosscher K (2013) How glucocorticoid receptors modulate the activity of other transcription factors: A scope beyond tethering. Mol Cell Endocrinol 380: 41-54. doi:10.1016/j.mce.2012.12.014

Reiner GC, Katzenellenbogen BS (1986) Characterization of estrogen and progesterone receptors and the dissociated regulation of growth and progesterone receptor stimulation by estrogen in MDA-MB-134 human breast cancer cells. Cancer Res 46: 1124-1131.

Ringnér M, Fredlund E, Häkkinen J, Borg Å, Staaf J (2011) GOBO: Gene expression-based outcome for breast cancer online. Plos One 6: e17911. doi:10.1371/journal.pone.0017911

Ross-Innes CS, Stark R, Holmes KA, Schmidt D, Spyrou C, Russell R, Massie CE, Vowler SL, Eldridge M, Carroll JS (2010) Cooperative interaction between retinoic acid receptor- $\alpha$ and estrogen receptor in breast cancer. Genes Dev 24: 171-182. doi:10.1101/gad.552910

Sarbassov DD, Guertin DA, Ali SM, Sabatini DM (2005) Phosphorylation and regulation of Akt/PKB by the rictor-mTOR complex. Science 307: 1098-1101. doi:10.1126/science.1106148

Saville B, Wormke M, Wang F, Nguyen T, Enmark E, Kuiper G, Gustafsson JA Safe S (2000) Ligand-, cell-, and estrogen receptor subtype $(\alpha / \beta)$-dependent activation at GC-rich (Sp1) promoter elements. J Biol Chem 275: 5379-5387. doi:10.1074/jbc.275.8.5379

Schmidt D, Wilson MD, Spyrou C, Brown GD, Hadfield J, Odom DT (2009) ChIPseq: Using high-throughput sequencing to discover protein-DNA interactions. Methods 48: 240-248. doi:10.1016/j.ymeth.2009.03.001

Schoknecht T, Schwinge D, Stein S, Weiler-Normann C, Sebode M, Mucha S, Otto B, Ellinghaus E, Stahl F, Franke A, et al (2017) CD4+ T cells from patients with primary sclerosing cholangitis exhibit reduced apoptosis and down-regulation of proapoptotic Bim in peripheral blood. J Leukoc Biol 101: 589-597. doi:10.1189/jlb.5a1015-469r

Seipel K, Georgiev O, Schaffner W (1992) Different activation domains stimulate transcription from remote ("enhancer") and proximal ("promoter") positions. EMBO J 11: 4961-4968.

Shabestari RM, Safa M, Alikarami F, Banan M, Kazemi A (2017) CREB knockdown inhibits growth and induces apoptosis in human pre-B acute lymphoblastic leukemia cells through inhibition of prosurvival signals. Biomed Pharmacother 87: 274-279. doi:10.1016/j.biopha. 2016.12.070

Shankar DB, Cheng JC, Sakamoto KM (2005) Role of cyclic AMP response element binding protein in human leukemias. Cancer 104: 1819-1824. doi:10.1002/cncr.21401

Shukla A, Bosenberg MW, MacPherson MB, Butnor KJ, Heintz NH, Pass HI, Carbone M, Testa JR, Mossman BT (2009) Activated cAMP response element binding protein is overexpressed in human mesotheliomas and inhibits apoptosis. Am J Pathol 175: 2197-2206. doi:10.2353/ ajpath.2009.090400

Smith CL, Conneely OM, O'Malley BW (1993) Modulation of the ligandindependent activation of the human estrogen receptor by hormone and antihormone. Proc Natl Acad Sci USA 90: 6120-6124. doi:10.1073/ pnas.90.13.6120

Swinstead EE, Miranda TB, Paakinaho V, Baek S, Goldstein I, Hawkins M, Karpova TS, Ball D, Mazza D, Lavis LD, et al (2016a) Steroid receptors reprogram FoxA1 occupancy through dynamic chromatin transitions. Cell 165: 593-605. doi:10.1016/j.cell.2016.02.067

Swinstead EE, Paakinaho V, Presman DM, Hager GL (2016b) Pioneer factors and ATP-dependent chromatin remodeling factors interact dynamically: A new perspective: Multiple transcription factors can effect chromatin pioneer functions through dynamic interactions with ATP-dependent chromatin remodeling factors. Bioessays 38 : 1150-1157. doi:10.1002/bies.201600137

Tora L, Mullick A, Metzger D, Ponglikitmongkol M, Park I, Chambon P (1989) The cloned human estrogen receptor contains a mutation which alters its hormone binding properties. EMBO / 8: 1981-1986. 
Voss TC, Schiltz RL, Sung MH, Yen PM, Stamatoyannopoulos JA, Biddie SC, Johnson TA, Miranda TB, John S, Hager GL (2011) Dynamic exchange at regulatory elements during chromatin remodeling underlies assisted loading mechanism. Cell 146: 544-554. doi:10.1016/j.cell.2011.07.006

Webb P, Nguyen P, Shinsako J, Anderson C, Feng W, Nguyen MP, Chen D, Huang SM, Subramanian S, McKinerney E, et al (1998) Estrogen receptor activation function 1 works by binding p160 coactivator proteins. Mol Endocrinol 12: 1605-1618. doi:10.1210/me.12.10.1605

Wilson BE, Mochon E, Boxer LM (1996) Induction of bcl-2 expression by phosphorylated CREB proteins during B-cell activation and rescue from apoptosis. Mol Cell Biol 16: 5546-5556. doi:10.1128/mcb.16.10.5546

Yang F, Ma Q, Liu Z, Li W, Tan Y, Jin C, Ma W, Hu Y, Shen J, Ohgi KA, et al (2017) Glucocorticoid receptor:MegaTrans switching mediates the repression of an ERQ-regulated transcriptional program. Mol Cell 66: 321-331. doi:10.1016/j.molcel.2017.03.019

Zhang X, Odom DT, Koo SH, Conkright MD, Canettieri G, Best J, Chen H, Jenner R, Herbolsheimer E, Jacobsen E, et al (2005) Genome-wide analysis of cAMP-response element binding protein occupancy, phosphorylation, and target gene activation in human tissues. Proc Natl Acad Sci USA 102: 4459-4464. doi:10.1073/pnas. 0501076102

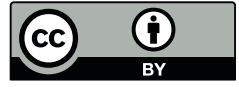

License: This article is available under a Creative Commons License (Attribution 4.0 International, as described at https://creativecommons.org/ licenses/by/4.0/). 